\title{
The recurrence theorem of Frenet formulae
}

\section{ABEL CAVAŞI}

\section{ABSTRACT.}

In this paper we generalize Frenet trihedron and we provide some other classes of trihedrons, called Frenet trihedrons of order $n, n \geq 1$. Moreover we prove that those trihedrons can be defined recurrently and we emphasize their role in the study of the generalized helices of order $n$. As practical applications we present the influence of the recurrence theorem in some interdisciplinary domains like physics, chemistry and biology.

Acknowledgements. Many thanks to Mrs. Teacher of Mathematics Alina-Ramona Baias, who made considerable effort to translate and adapt this work from Romanian.

\section{REFERENCES}

[1] Barros, M. General Helices and a Theorem of Lancret, Proc. Amer. Math. Soc., 125 (1997), No. 5, 1503-1509

[2] Frenet, F. (1847), Sur les courbes à double courbure, Thèse, Toulouse. Abstract in J. de Math., 17 (1852)

[3] Hacisalihoglu, H. H., Differential Geometry, Ankara University, 12 (13) (2012), 73 Faculty of Science Press, 2000

[4] Izumiya, S. and Takeuchi, N., New special curves and developable surfaces, Turk. J. Math, 28, (2004), 531-537

[5] Liu, H. and Wang, F., Mannheim partner curves in 3-space, Journal of Geometry, col. 88, nr. 1-2, pp 120-126, (2008)

[6] Monterde, J., Salkowski curves revisted: A family of curves with constant curvature and non-constant torsion, Comput. Aided Geomet. Design, 26 (2009), 271-278

[7] Ramis, C., Uzunoglu, B. and Yayli, Y., New Associated Curves k-Principle Direction Curves and $N_{k}$ Slant Helix, arXiv:1404.7369 [math.DG], (2014)

[8] Scofield, P. D., Curves of constant precession, Amer. Math., Monthly, Vol. 102, (1995), pp 531-537, MR 96d:53002

[9] Serret, J. A. Sur quelques formules relatives à la théorie des courbes à double courbure, J. de Math., 16 (1851)

[10] Uzunoglu, B., Gok, I. and Yayli, Y., A New Approach on Curves of Constant Precession, arXiv:1311.4730 [math.DG], (2013)

[11] Yayli, Y. and Saracoglu, S., Characterizations of Special Curves, arXiv:1202.0133 [math.DG], (2012)

[12] Yayli, Y. and Ziplar, E., On slant helices an general helices in euclidean n-space, Mathematica Aeterna, Vol. 1 (2011), Nr. 08, 599-610

[13] Ziplar, E., Senol, A. and Yayli, Y., On Darboux Helices in Euclidean 3-Space, Global J. of Science Frontier Research, 12(13) (2012), 73-80

WEST UNIVERSITY OF TIMIŞOARA

FACUlTY OF MATHEMATICS AND COMPUTER SCIENCE

ROMANIA

E-mail address: abel.cavasi@gmail.com 